\title{
Rancang Bangun Miniatur Constant Current Regulator Augier Diam 4000 Sebagai Media Pembelajaran di Politeknik Penerbangan Surabaya
}

\author{
Hartono \\ Kurniawan Rizky \\ Program Studi Diploma III Teknik Listrik Bandar Udara \\ Politeknik Penerbangan Surabaya \\ Jl. Jemur Andayani 1/73 Wonocolo Surabaya 60236 \\ Email: hartono.asempapan@gmail.com
}

\begin{abstract}
ABSTRAK
Constant Current Regulator adalah sebuah alat yang digunakan untuk pengatur arus konstan dan brightness dari alat bantu visual yang ada pada Airfield Lighting. Untuk melengkapi peralatan praktikum di Politeknik Penerbangan Surabaya, maka dirancanglah sebuah trainer Constant Current Re gulator sebagai media pembelajaran. Rancangan sebuah miniatur Constant Current Regulator dengan menggunakan mik rokontroller sebagai komponen utama untuk mengendalikan besar arus yang men galir pada rangkaian beban. Hasil pengukuran dari sensor arus akan memberikan data kepada mikrokontroller sebagai bahan pertimbangan jika arus telah sesuai dengan referensi arus yang telah ditetapkan, apabila arus yang diukur tidak sesuai dengan arus referensi maka mik rokontroller akan mengendalikan Solid-State Relay yang berfungsi sebagai switch untuk mengendalikan beban.

Kata kunci : constant current regulator, mikrokontroller, sensor arus, Solid-State Relay, arus referens

ABSTRACT

Constant Current Regulator is a tool used for regulating the constant of current and the brightness of the visual aids of Airfield Ligtings. Currently there is no practical tool in the Aviation Polytechnics of Surabaya, so it is necessary to design a trainer Constant Current Regulators as a learning media. Therefore, it has been designed a miniature of Consatant Current Regulator using a microcontroller as the main component for controlling the current which is flowing in the load circuit. The mea surement results of current sensors will provide data to the microcontroller for consideration if the current is appropriate with the predetermined reference current, if the measured current does not appropriate to the reference current, the microcontroller will control Solid-State Relay which serves as a switch to control current the load.
\end{abstract}

Keywords : constant current regulator, microcontroller, current sensor, Solid - State Relay, reference current

\section{Latar Belakang}

Dalam dunia penerbangan tersedianya suatu power supply yang kontinyu dan juga handal sangat dibutuhkan. Selain power supply yang kontinyu juga dibutuhkan SDM yang memiliki kecakapan dan juga ahli di bidang penyediaan power supply untuk bandar udara.

Untuk memenuhi kriteria/ ketentuan yang telah ditetapkan,maka rangkaian/instalasi alat bantu pendaratan visual pada umumnya dibuat dalam rangkaian seri dengan intensitas cahaya

dipertahankan tetap. Agar pancaran intensitas cahaya dari alat bantu pendaratan visual tetap, dibutuhkan supply arus yang tetap/konstan. Pelaksanaannya yaitu sumber catu daya dihubungkan dengan input peralatan regulator arus tetap. Alat penunjang yang diperlukan untuk mengontrol agar arus tetap pada Airfield Lighting adalah Constant Current Regulator atau lebih dikenal dengan CCR. 
Politeknik Penerbangan Surabaya merupakan suatu lembaga pendidikan dan pelatihan yang khusus untuk mencetak insan-insan penerus bangsa yang berkompeten, terampil, berdedikasi, kreatif dan beretika, sehingga dapat bersaing di pasar kerja di dunia penerbangan yang lingkupnya sangat luas dan tidak memberikan ruang atau tempat bagi segala bentuk kesalahan.

Untuk menghasilkan lulusan yang mampu menguasai ilmu pengetahuan dan teknologi dan mampu menganalisis setiap permasalahan, maka Program Studi Teknik Listrik Bandar Udara menyediakan sarana laboratorium yang dapat digunakan oleh taruna dalam mengaplikasikan ilmu terapan yang telah diperoleh dari teori yang didapatkan dari proses pembelajaran di kelas sehingga kelak dapat dihasilkan lulusan yang memiliki wawasan dan keterampilan sesuai dengan disiplin ilmu yang telah diajarkan dan dapat mengaplikasikannya di dunia kerja sesuai salah satu misi dari Politeknik Penerbangan Surabaya yaitu mencetak sumber daya manusia yang unggul di bidang penerbangan yang memenuhi standar kompetensi dan mampu bersaing di tingkat nasional maupun global.

Dalam penyampaian teori maupun praktek tentang Constant Current Regulator dengan menggunakan trainer CCR yang dilengkapi dengan sistem kontrol dan sistem kelistrikannya sangat diperlukan guna menunjang proses pembelajaran sehingga memberikan kemudahan bagi dosen maupun instruktur pengajar dalam penyampaian materi pembelajaran dan dapat memperdalam wawasan pengetahuan taruna, sehingga taruna lebih memahami dan dapat menerapkan ilmu yang telah diterima.

Dari latar belakang yang telah dijelaskan diatas, maka penulis mengambil judul penelitian: "Rancang Bangun Miniatur Constant Current Regulator AUGIER DIAM 4000 Sebagai Media Pembelajaran di Politeknik Penerbangan Surabaya". Peralatan ini dapat digunakan untuk praktikum dan dapat untuk mempelajari CCR dengan praktis dan juga untuk mengoptimalkan pembelajaran taruna taruni untuk menghasilkan lulusan yang handal sehingga mampu bersaing di dunia kerja.

\section{Kondisi Saat Ini}

Di laboratorium AFL (Airfield Lighting) terdapat beberapa alat untuk menunjang mata kuliah Sistem Penerangan Bandara seperti, miniatur Airfield Lighting Orange Airport, Simulator Airfield Lighting, dan Illuminance Light Meter. Peralatan praktek di laboratorium AFL tersebut sebenarnya sudah sangat lengkap, tetapi masih ada beberapa peralatan yang masih kurang maksimal dalam penggunaanya. Sebagai contoh miniatur Airfield Lighting, lampu penerangan airside sudah dirangkai seri antar lampu dengan trafo seri yang sesuai dengan ada yang di lapangan. Akan tetapi untuk CCR yang telah terpasang sebagai catu daya utama bagi penerangan airside tersebut tidak untuk dibongkar dan dipasang. Maka dari itu penulis ingin merancang sebuah miniatur Constant Current Regulator AUGIER DIAM 4000 sebagai sarana pembelajaran di Politeknik Penerbangan Surabaya. 


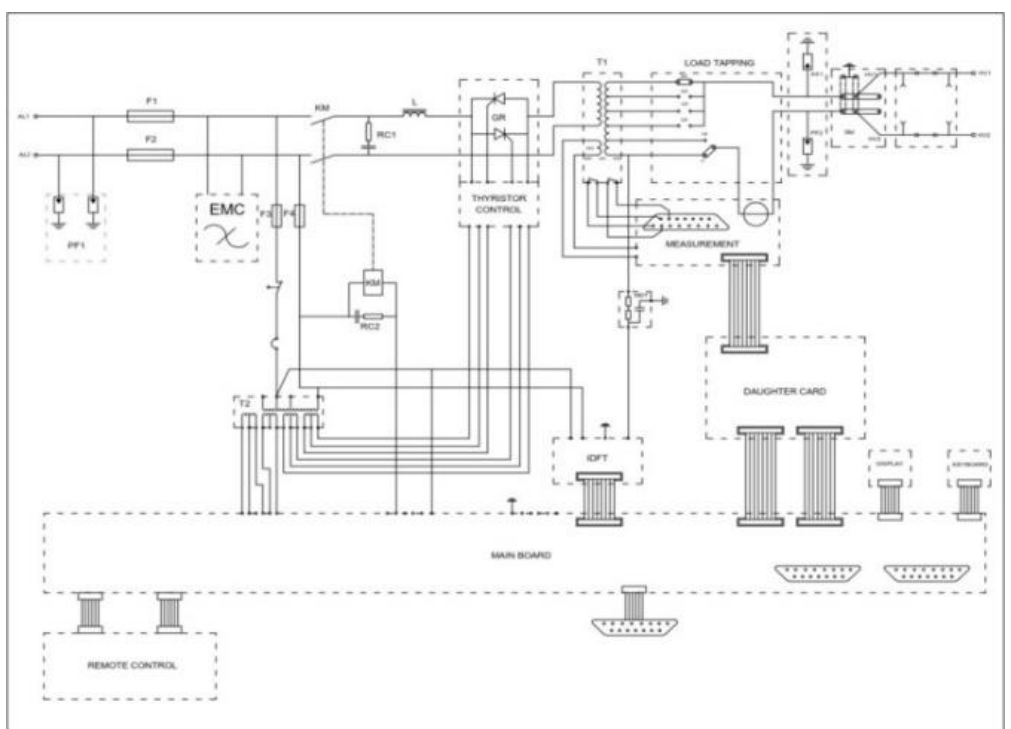

Gbr. 1 Rangkaian sistem secara keseluruhan CCR AUGIER DIAM 4000

Berikut adalah blok diagram dari CCR AUGIER DIAM 4000 :

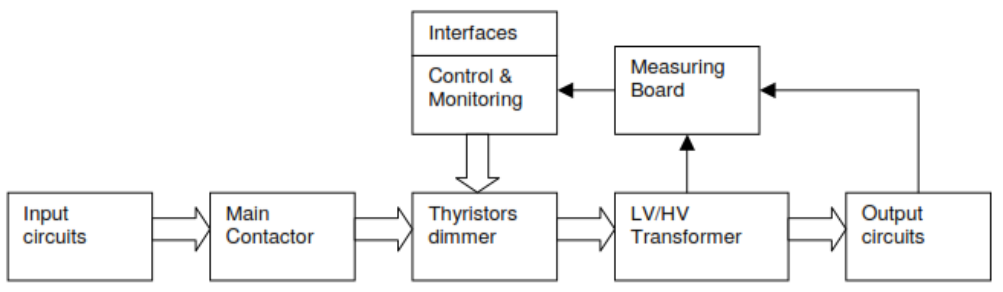

Gbr. 2.Blok Diagram CCR AUGIER DIAM 4000

\section{Kondisi Yang Diinginkan}

Di Laboratorium AFL belum ada trainer CCR yang bisa dibongkar dan dipasang kembali sebagai sarana pembelajaran, sehingga dengan memanfaatkan ilmu yang telah dipelajari, penulis ingin membuat suatu rancangan miniatur dari sebuah CCR sebenarnya yang bisa dipelajari prinsip dasar dan cara kerja suatu CCR dengan menggunakan mikrokontroller. Dari SSR nantinya akan masuk ke tapping trafo pada output yang dapat diatur sesuai dengan daya dari beban yang terpasang.

Rancangan alat yang akan dibuat nantinya adalah pengontrolan brightness lampu pada miniatur CCR type AUGIER DIAM 4000 menggunakan mikrokontroler arduino. Dalam rancangan ini mengembangkan sistem kontrol CCR type AUGIER DIAM 4000 yang masih menggunakan transistor akan dimodifikasi dengan mikrokontroler arduino untuk mewakili fungsi yang ada pada transistor. Sehingga dalam penerapannya juga dalam pengerjaannya lebih mudah dan sederhana. 


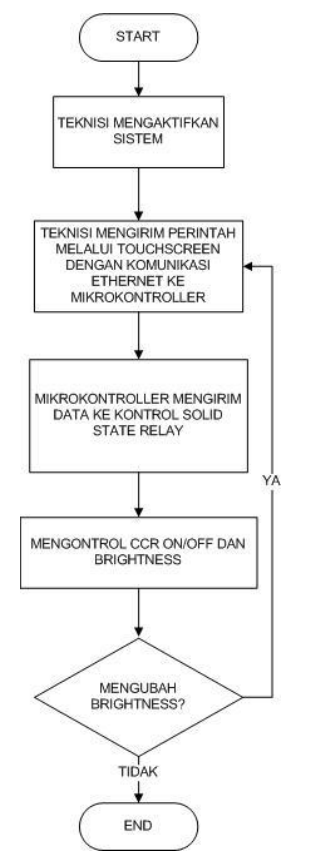

Gbr. 3. Flowchart Rangkaian Kontrol

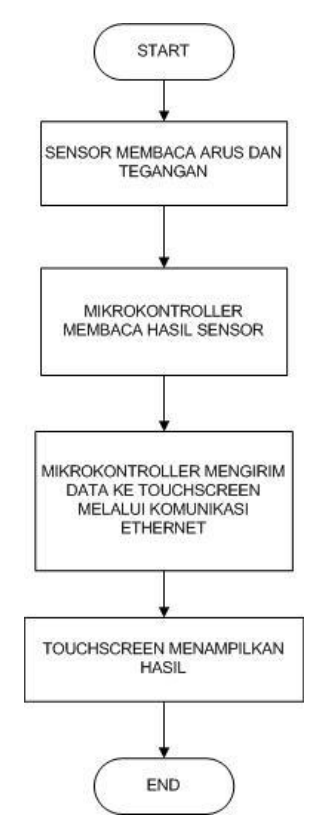

Gbr. 4. Flowchart Rangkaian Monitoring

\section{Konsep Rancangan}

Untuk menyusun suatu miniatur/trainer yang hasilnya sesuai dengan yang diharapkan, maka diperlukan adanya suatu konsep rancangan untuk memberikan gambaran yang akan dirancang nantinya.

Untuk itu penulis membuat diagram blok untuk menggambarkan miniatur yang akan dirancang.

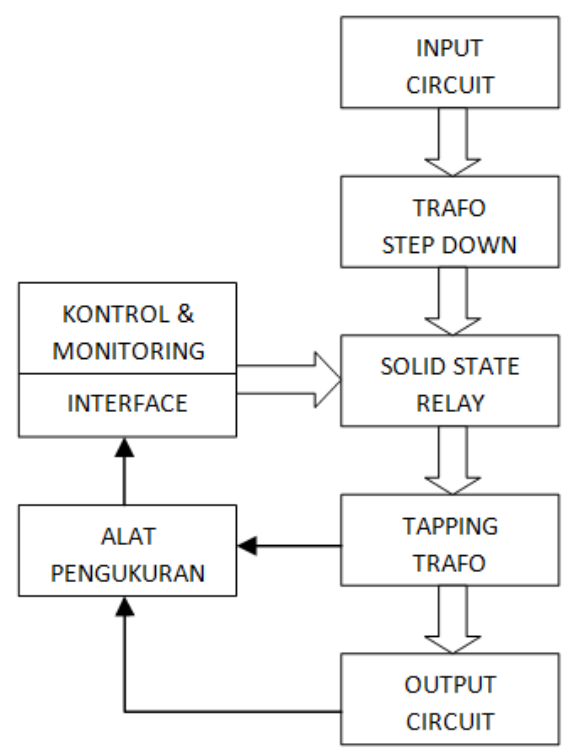

Gbr.5. Blok Diagram Rancangan 
Dari blok diagram diatas dijelaskan bahwa sumber utama dari sistem berasal dari jala - jala 220VAC yang kemudian diturunkan menggunakan transformator menjadi 50VAC. Keluaran dari trafo tersebut menjadi input bagi Solid State Relay yang telah disesuaikan. Solid State Relay berfungsi sebagai switching yang nantinya bekerja layaknya saklar dengan kecepatan tinggi, dimana Solid State Relay akan memotong gelombang sinusoida yang dihasilkan oleh tegangan AC. Dengan memutus gelombang sinusoida maka arus yang diinginkan bisa didapat.

Pada trafo daya juga akan dirancang tapping load adaptation yang berfungsi untuk mengoptimalkan efisiensi faktor daya. Pelaksanaanya yaitu dengan cara merubah tap pada output sekunder di trafo daya. Direkomendasikan untuk memilih tap yang rendah apabila CCR dioperasikan dibawah beban penuh. Pengaturan tap pada beban sebenarnya memberikan 4 manfaat :

1. Input arus utama menurun

2. Harmonik yang terdapat pada input arus utama menurun

3. Maksimum tegangan output pada kasus open circuit berkurang

4. Maksimum arus output pada kegagalan Solid State Relay akan dibatasi

Dari load tapping pada trafo daya arus akan mengalir ke trafo tegangan $1 / 1$ yang nantinya akan mewakili fungsi dari trafo seri pada kondisi sebenarnya, karena lampu-lampu yang digunakan sebagai beban nantinya dirangkai secara seri, maka trafo tersebut akan berfungsi untuk mencegah agar kerusakan/trouble pada salah satu lampu tidak akan mempengaruhi kondisi pada lampu yang terpasang lainnya.

Pada rangkaian beban akan dipasang sensor arus yang berfungsi untuk menerima data arus yang dihasilkan dari output CCR. Nilai arus yang terbaca akan digunakan sebagai acuan penentuan lebar gelombang pulsa yang akan dihasilkan oleh PWM pada Arduino yang digunakan untuk kontrol Solid State Relay nantinya.

\section{Pengujian dan Analisa}

Pengujian ini dilakukan untuk mengetahui kinerja dari sistem dan untuk mengetahui apakah sistem yang telah dibuat sesuai dengan perencanaan atau belum. Pengujian terlebih dahulu dilakukan secara terpisah pada masing-masing unit rangkaian, kemudian dilanjutkan ke pengujian sistem yang telah terintegrasi secara keseluruhan. Adapun tahap-tahap pengujian yang akan dilakukan adalah sebagai berikut :

1. Pengujian Tegangan Input

2. Pengujian Tegangan Output

3. Pengujian Arus dan Brightness

\section{Pengujian Tegangan Input}

Pengujian tegangan input dilakukan dengan mengatur tegangan keluaran dari transformator variabel yang diatur sekitar 50VAC. Pengujian ini bertujuan untuk menyesuaikan tegangan kerja pada rancangan nantinya. Maka dari itu tegangan yang diukur harus benar-benar sesuai agar tidak berakibat pada kinerja rancangan tersebut nantinya. 


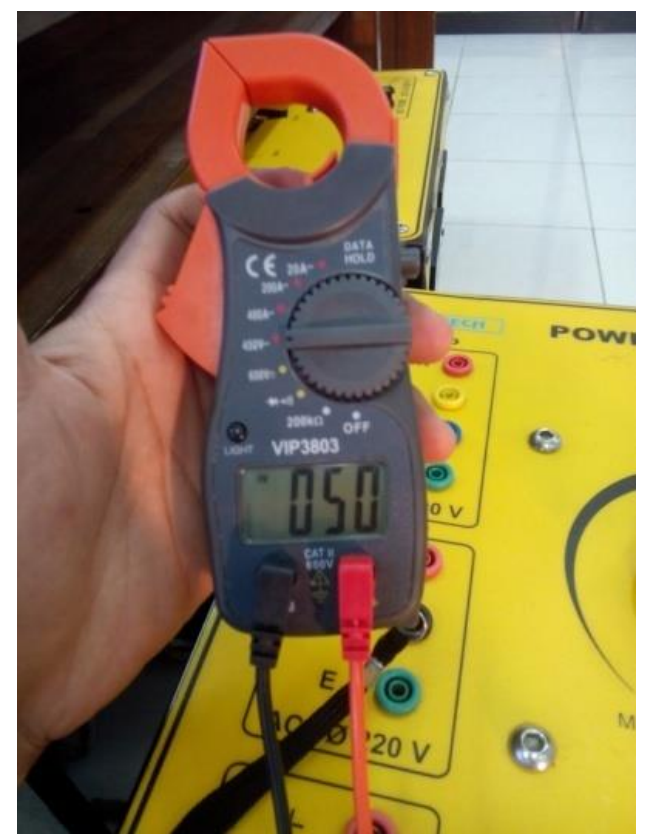

Gbr. 6. Pengujian Tegangan Input

\section{Pengujian Tegangan Output}

Pengujian Tegangan Output bertujuan untuk mengetahui tegangan keluaran dari Transformator 4A Step Up dari 50V ke 220V. Nilai tegangan input 50V dari Trafo tersebut didapat dari output Transformator Variabel, sehingga tegangan dapat diatur sesuai kebutuhan.

Pengujian ini dilakukan dengan menghubungkan Transformator Variabel dengan Trafo Step Up, kemudian output dari Trafo Step Up dihubungkan dengan Voltage Meter untuk mengukur tegangan keluarannya.

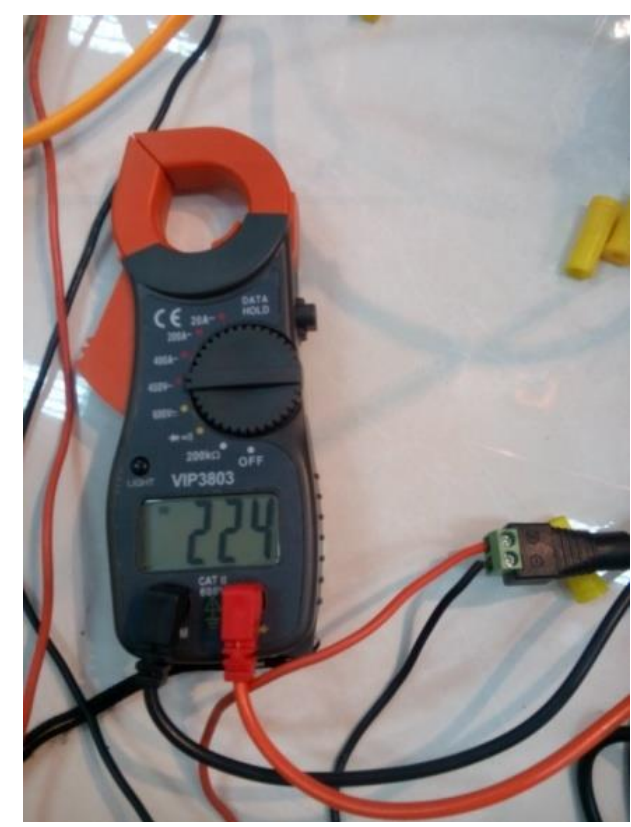

Gbr.7.Pengujian Tegangan Output 
Tabel 1. Pengukuran Arus

\begin{tabular}{|c|c|}
\hline BRIGHTNESS & ARUS \\
\hline 1 & 0.05 \\
\hline 2 & 0.07 \\
\hline 3 & 0.10 \\
\hline 4 & 0.12 \\
\hline 5 & 0.15 \\
\hline
\end{tabular}

\section{KESIMPULAN DAN SARAN}

\section{Kesimpulan}

Setelah merancang Trainer Constant Current Regulator menggunakan kontrol Arduino UNO sebagaimana yang telah dijelaskan pada bab-bab sebelumnya maka dapat diambil kesimpulan yaitu :

1. Untuk mendapat arus konstan menggunakan sensor arus ACS 712 dan mikrokontroller Arduino UNO serta menggunakan Solid State Relay sebagai switching untuk penyakelaran.

2. Dengan menggunakan metode kontrol PWM, arus konstan dapat diatur sesuai dengan perubahan beban, dengan cara memutus gelombang sinusoida tegangan AC agar arus dapat berubah sesuai dengan beban.

3. Untuk mengatur brightness dari lampu tersebut dapat digunakan dengan mengatur lebar dari gelombang pulsa yang dihasilkan oleh Arduino.

\section{Saran}

1. Untuk mengatur PWM agar lebih stabil, sebaiknya dapat ditambahkan dengan kontroler PID (Proporsional Integral Deriativ).

2. Arus yang dikontrol sebaiknya dapat diperbesar lagi agar lebih mudah dalam dimengerti dan dipahami oleh peserta didik.

3. Alat yang dikembangkan harus mempunyai desain dan konstruksi yang lebih baik dan kuat agar dapat bertahan dalam jangka waktu yang lama.

\section{DAFTAR PUSTAKA}

AM.06.3503-MW Instruction Manual ADB.

Visual Aids, Arerodrome Design Manual, International Civil Aviation Organization

http://ecmweb.com/content/series-lighting-circuitry-why-use-it,

Web.arduino.com 